\title{
REPELATION POTENCY OF N-HEXANE EXTRACT OF BASIL LEAF AND STEM (OCIMUM BASILICUM L.) AGAINST CULEX QUINQUEFASCIATUS
}

\author{
Indri Ramayanti ${ }^{*}$, Miranti Dwi Hartanti², Reynaldi Aulia Rahman ${ }^{3}$
}

\begin{abstract}
1Department of Parasitology, Faculty of Medicine, Universitas Muhammadiyah Palembang, Palembang, Indonesia 2Department of Pharmacology, Faculty of Medicine, Universitas Muhammadiyah Palembang, Palembang, Indonesia ${ }^{3}$ Medical Study Program, Faculty of Medicine, Universitas Muhammadiyah Palembang, Jalan KH. Balqi, 13 Ulu, Palembang 30 Universitas Muhammadiyah Palembang, Palembang, Indonesia
\end{abstract} indri ramayanti@um-palembang.ac.id

\begin{abstract}
The Culex quinquefasciatus mosquito is the main vector of filariasis and a popular effort to control it in society is by using chemical materials, but they cause toxic effects in humans, so it is necessary to use a repelant from natural ingredients, one of which is basil containing essential oils and proven to be effective as a repelant against mosquito. The objective of this research was to determine repelant power of n-hexane extract of basil leaves and stems against the Culex quinquefasciatus. This study was a laboratory experimental study using a completely randomized design, with 3 replications at 7 time intervals. The extract concentrations were $15 \%, 25 \%$, $35 \%$ and ethanol negative control 96\%, the positive control repelant X containing $13 \%$ DEET. The results showed that the n-hexane extract of basil leaves and stems for 6 hours at a concentration of $15 \%$ was able to resist $75 \%$ of mosquito, a concentration of $25 \%$ was able to resist as much as $85.05 \%$, and a concentration of $35 \%$ was able to resist as much as $92.51 \%$, the one-way ANOVA analysis showed that the value of $p=0.000(p<0,05)$, meaning that there was a difference in the number of Culex quinquefasciatus perching on the black cloth at various concentrations of n-hexane extracts of leaves and stems of basil, while the probit analysis showed that the effective extract concentration at $90 \%$ was $31.52 \%$. The extract of $n$-hexane leaves and basil stems was effective as a repelant against the Culex quinquefasciatus.
\end{abstract}

Keywords: Concentration, essential oil, mosquitoes, repelant 


\section{INTRODUCTION}

The existence of Culex spp mosquito spreads almost throughout the world, particularly those found in tropical and sub-tropical areas (Nchoutpouen et al., 2019). One of the species with the widest distribution is Culex quinquefasciatus. (Samy et al., 2016). In Indonesia, the Culex spp mosquito, especially the Culex quinquefasciatus species, is evenly distributed, especially in the areas of Sumatra, Java, Sulawesi, Kalimantan, NTT and Irian Jaya (Lee and Ryu, 2019). The Culex quinquefasciatus mosquito is an important species and intelligent vector due to its high adaptive ability, ecological plasticity, invasive behavior, host specificity and ability (Yee and Skiff, 2014).

Culex quinquefasciatus mosquito can be prevented by using natural ingredients without having to use chemical insecticides such as repelants containing the active ingredient $\mathrm{N}$, Dethylmeta-Toluamide (DEET) (Deletre et al., 2019). Natural materials that can be used as botanical insecticides include leaves, stems, seeds, and flowers from plants that can be processed into mosquito repelant materials 12 . The insecticidal materials derived from plants are guaranteed safe for the environment because they decompose quickly on the ground and do not harm animals, humans or insects that are not targeted 3,4 . Plants that are potential as botanical insecticides generally have a characteristic of bitter taste because they contain alkaloids and terpenoids, have a bad smell and taste a bit spicy 5 . ${ }^{6}$. This plant is rarely attacked by pests so it is widely used as an extract of vegetable insecticides in organic agriculture 7.

A plant considered to be a botanical insecticide is basil (Ocimum basilicum). It is one of the indigenous plants widely grown in Indonesia and is commonly used as a seasoning for cooking and medicine because it contains essential oils ${ }^{8}$. The results of phytochemical study on the basil have proven the existence of flavonoids, alkaloids, saponins, phenols, and essential oils containing eugenol (70.5\%) as the main component ${ }^{9} 10$. The active compounds contained in the basil are effective as insecticides, including flavonoids functioning as respiratory toxins, saponins as stomach and contact poisons, and eugenol having a role in denaturing cytoplasmic proteins and tissue necrosis in insects 11,12. The combination of these active compounds composition hypothetically makes basil can be used as a natural alternative repelant 13 .

Based on the above introduction, the basil leaf extract in mosquito repelant preparations shows a potent activity as a vegetable insecticide. This study aimed to find out the repelant power of basil extract (Ocimum basilicum) using an n-hexane solvent against Culex quinquefasciatus mosquito. 


\section{METHODS}

\section{Research Design}

This study is a laboratory experimental study with a Completely Randomized Design (CRD). This research was conducted at the Parasitology Laboratory of the Faculty of Medicine, Universitas Muhammadiyah Palembang in October - November 2019.

\section{Population and Sample}

The population in this study was the Culex quinquefasciatus mosquito obtained from the Lokalitbang P2B2 Entomology Laboratory Baturaja OKU, South Sumatra. The number of samples used was 375 mosquito with 3 repetitions in 5 treatment groups. Ethical approval was obtained from the Ethical Committee of the Faculty of Medicine Muhammadiyah University Palembang.

\section{Mosquito Rearing}

Culex quinquefasciatus eggs obtained from the Lokalitbang P2B2 Entomology Laboratory were hatched in a plastic tub $35 \times 25 \times 5 \mathrm{~cm}^{3}$ in size filled with aquades three fourth of the plastic tub. The hatched larvae were reared until they become adult mosquito. During their development, the larvae were given fed fish pellets. The rearing process was carried out in mosquito cages. After that, female mosquito were separated them from the male The females were transferred to the test cage using an aspirator. It took 5 test cages $30 \times 30 \times 30 \mathrm{~cm}$ in size, with 25 Culex quinquefasciatus in each cage. They were reared until they reach the age of 5-7 post-emergence days, during which time the mosquito were fed sugar solution ${ }^{14}$.

\section{Simplicia and Extract Processing}

One kilogram of fresh basil leaves and stems were washed and separated. Then, they were hung to dry. After the drying process, they were refined using blender to get $500 \mathrm{~g}$ of simplicia powder. The extraction process is by maceration using n-hexane solvent. The simplicia powder was put into a maceration jar and two litre of $n$-hexane liquid is added until the powder is immersed in the solvent. It was, then stirred several times and was left for 24 hours at room temperature. Frequently stirrings were done while it was left in the room. The procedure was repeated 3 times and followed with evaporation to get thick extract. The thick extract was then diluted by adding $96 \%$ ethanol to obtain a concentration of $15 \%, 25 \%$ and $35 \%$. The negative controls, which were, ethanol (96\%), and n-hexane extract, were added. The positive control used was repelant X containing $13 \%$ DEET and it was added into a $25 \mathrm{~mL}$ spray bottle. The number of sprays were counted for each treatment. 


\section{Repelant Activity Test}

The repelant activity test method is the Standard Method of Household Pesticide Efficacy Testing. The repelant test guideline is to use a black cloth with the size of the test cage wall. It was attached to the surface of the wall. Into the surface of the cloth, the positive control, negative control, n-hexane were sprayed on each black cloth. Twenty-five mosquito were then put into each cage. They were observed and the number of mosquito that land on the cloth for 5 minutes per hour were counted. They were counted from the first hour (immediately after application) to the sixth. The same treatment was performed using different black cloth and different mosquito for 3 times ${ }^{15}$. At the end of the test, the percentage of repulsion is assessed as the proportion of the number of mosquito landing on the treatment cloth with the number of mosquito landing on the control cloth. It is calculated with the following formula :

Repulsion Strength (RS) $=(\mathrm{K}-\mathrm{R}) / \mathrm{K} \times 100 \%$

Where:

$\mathrm{K}$ : Number of landing on the negative control cloth

$\mathrm{R}$ : The number of landing on the treated cloth

After obtaining the percentage of repulsion strength at each concentration, the effective concentration was assessed to obtain a percentage of $90 \%$ repulsion strength.

\section{Data Analysis}

Probit analysis was used to determine the effective concentration 90\% (EC90), i.e. the concentration of the extract that can reject the mosquito population by $90 \%$ for 6 hours of treatment with a $95 \%$ confidence level.

\section{RESULTS AND DISCUSSION}

\section{Repellent Activity}

The results from data the analysis shown the percentage of repelantion strength of n-hexane extracts from basil (Ocimum basilicum) toward the Culex quinquefasciatus mosquito at concentrations of $15 \%, 25 \%$, and $35 \%$ (Table 1), shows that there is a simultaneous increase in both the mean percentage of repulsion to contact with Culex quinquefasciatus and in the concentration of $n$-hexane extracts at the highest concentrations of $15 \%, 25 \%$, and $35 \%$. The number of Culex quinquefasciatus mosquito that perched for 6 hours of treatment at a concentration of $15 \%$ was able to resist the mosquitoes that landed as much as $75 \%$, a concentration of $25 \%$ was able to reject as much as $85.05 \%$, and a concentration of $35 \%$ was able to reject as much as $92.51 \%$ approaching the repellant activity value of positive control. 
Table 1 Repelantion Strength

\begin{tabular}{cccccc}
\hline \multirow{2}{*}{ Repetition to- } & \multicolumn{5}{c}{ Percentage of Repelantion Strength (\%) } \\
\cline { 2 - 6 } & $15 \%$ & $25 \%$ & $\begin{array}{c}35 \% \\
\text { DEET 13\% }\end{array}$ & Control (-) etanol & Control (+) \\
\hline 1 & 75,00 & 84,56 & 91,66 & 0 & 98,21 \\
\hline 2 & 75,74 & 84,63 & 92,90 & 0 & 98,21 \\
\hline 3 & 74,26 & 85,98 & 92,98 & 0 & 98,83 \\
\hline Mean & 75,00 & 85,05 & 92,51 & 0 & 98,42 \\
\hline
\end{tabular}

The repulsion percentage of $n$-hexane extracts of basil leaves and stems with concentrations of 15\%, $25 \%$, and $30 \%$ against Culex quinquefasciatus mosquito were then performed statistical analysis using one-way ANOVA. One-way ANOVA test was conducted to determine the effect of n-hexane extract toward the percentage of repulsion. The results show that there were differences in the repelantion strength $(\mathrm{p}<0.05)$ at the concentration variation $(15 \%, 25 \%$ and $30 \%)$ in each time of the test. The difference in repulsion between the various concentrations of n-hexane extracts of leaves and basil stems is described below:

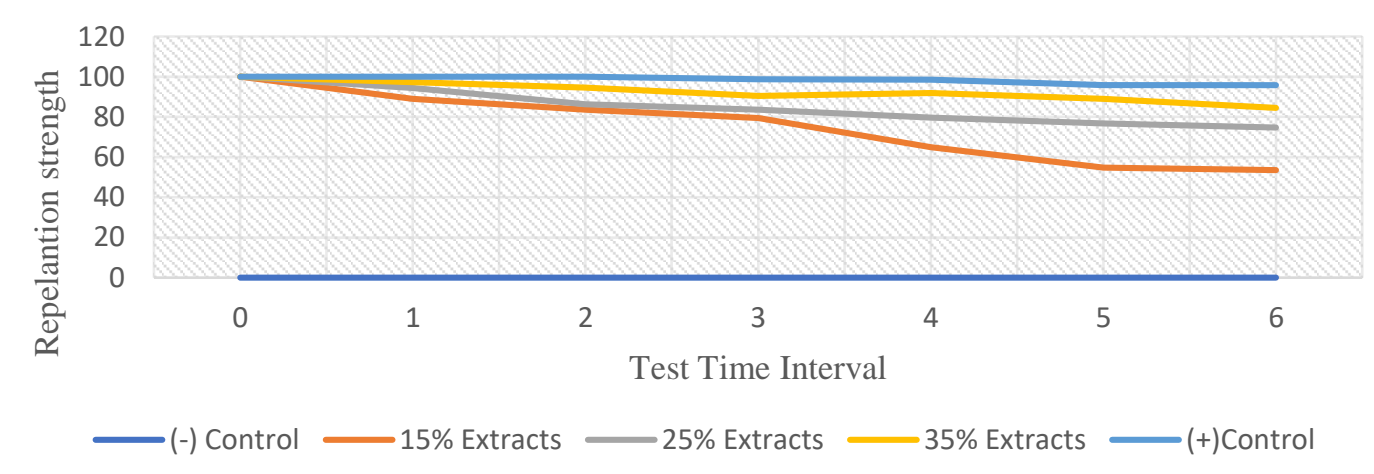

Figure 1. Concentration of N-Hexane Extract from Basil (Ocimum basilicum Linn.) effect plot as a repelant against Culex quinquefasciatus mosquito at seven testing time intervals.

The plot describes the variation in concentration with the repelantion strength of $\mathrm{n}$-hexane extracts at each test time period (Fiqure 1). It can be seen that the higher the concentration of the extract, the stronger the repulsion against Culex quinquefasciatus.

\section{Efectivity Concentration}

The estimation of the concentration with protective power was determined using the probit test. This study expected an Efectivity Concentration of 90\% (EC90). The probit analysis of the repelant 
effect of mosquito shows the EC90 value at 31.52\%. This indicates that at a concentration of 31.52\% within 6 hours it can repel $90 \%$ of the tested mosquito (Table 2).

Table 2. Concentration based on probit analysis

\begin{tabular}{|c|c|c|c|c|}
\hline \multirow{2}{*}{$\begin{array}{c}\text { Effectiveness } \\
(\%)\end{array}$} & \multirow{2}{*}{$\begin{array}{c}\text { Concentration } \\
(\%)\end{array}$} & \multirow{2}{*}{$\begin{array}{c}\text { Level of } \\
\text { significance }\end{array}$} & \multicolumn{2}{|c|}{ Interval significance } \\
\hline & & & Lower limit & Upper limit \\
\hline 90 & 31,52 & $95.0 \%$ & 25,48 & 56,65 \\
\hline
\end{tabular}

\section{DISCUSSION}

The number of Culex quinquefasciatus mosquito on the black cloth as shown in Table 1. it can be known that each concentration of extract $\mathrm{n}$-hexane basil leaves and stems (Ocimum basilicum ) has different repelantion strength, while in Figure 1. the influence of repelantion strength on Culex quinquefasciatus mosquito, it is seen that the increase in the repelantion strength of extract basil leaf and stems occurs simultaneously with the increase in the concentration of the applied exposians. This trend is seen to occur continuously from the beginning to the end of the testing period ( 0 hour to 6 hour). This indicates that the increase in the percentage of repelantion strength is directly proportional to the increase in the concentration of $n$-hexane extracts. The repulsion mechanism is that the higher the concentration of essential oils on the surface of the fabric that evaporates, the more active components in it which will result in the binding of the active component to the receptor ${ }^{16}$. In mosquito, their antennae and palp function as chemical sensors which are very sensitive and can easily be stimulated by chemical smells ${ }^{17}$. When the resulting fragrance evaporate into the air, it will be detected by the mosquito's olfactory receptor, and it will convert it into impulses and transmit it by the sensory nerve axons to the nerve centre (brain). As a result, the mosquito will keep away from the source of smell 18 .

The graph also shows that there is a difference in the repelantion strength of each test time interval, in which it decreased along with the increase in the time interval of the test, and it occurred in all treatment groups. This indicates that the decrease is also influenced by the interval of observation time. The longer the time interval, the more secondary repelant metabolite compounds from the extract that evaporate which decreases the concentration of molecules in the fabric, and in turn, it causes the protection to decrease ${ }^{19}$. The decrease can also be affected by the mosquito regulatory mechanism. The aroma of essential oils produced by basil extract will bind to its OBP (odorant binding proteins) which function as carriers for odour molecules into the mosquito's olfactory receptors ${ }^{20}$. The odours do not always circulate in mosquito lymph vessels but can also be degraded by the enzymes known as ODEs (odour- 
degrading enzymes). The rate of degradation depends on the molecules that bind to the OBP. ODEs function as regulators, especially if the odour molecules that bind to OBP's are excessive 21 .

The results of statistical analysis using probit analysis at the $95 \%$ confidence level show that EC 90 results at a concentration of $31.52 \%$ (Table 2). EC90 is the indication of the amount of concentration that has $90 \%$ repelantion strength of the mosquito population. This study showed that the n-hexane extracts (Ocimum basilicum) had an effect as a repelant against the mosquito.

The extract of $\mathrm{n}$-hexane from basil (Ocimum basilicum) leaves and stems contains eugenol, linalool, and geraniol ${ }^{22}$. The distinctive odour from the secondary metabolites such as linalool, geraniol, and eugenol will get into the mosquito extracellularly and are then captured by chemoreceptors on the sensilla located on the mosquito antenna. These molecules will bind to OBPs (Odorant Binding Proteins), and then will be carried by OBPs through the lymph in the sensilla to ORNs (Olfactory Receptor Neurons) ${ }^{23}$. In addition to carrying odour molecules, OBPs also function to dissolve these odour molecules and to select odour molecules to be accepted in certain ORs (olfactory receptors) 21. The odour will be converted into impulses transmitted by the sensory nerve axons to the nerve centre (brain) The mosquito avoid the source of the smell as the respond ${ }^{24}$. The odour molecule further interacts with extracellular G-protein-coupled receptors on ORs located in the dendrite of specific ORNs; where the intracellular G-protein-coupled receptors are active in turns and cause changes in the G-protein conformation 25. This causes nerve depolarization triggering the transmission of electrical impulses to the mosquito antenna lobe eliciting a rejection response or blocking the mosquito's sense of smell which ultimately acts as a barrier to the mosquito's performance to recognize its prey ${ }^{24}$.

Species of mosquito can affect the sensitivity in detecting odours that only low extract concentrations are effective against Culex quinquefasciatus mosquito with an estimated EC90 at a concentration of $31.52 \%$. The olfactory chemoreceptors of Culex quinquefasciatus is 6.9 times more sensitive to odours than other mosquito species such as Anopheles and An. albimanus ${ }^{26}$. In addition, the use of $n$-hexane solvent in the maceration of basil extracts also affects the bioactive compounds obtained. Several studies have shown that the use of n-hexane solvent yield more essential oils than other solvents. Studies on the effect of solvent types on the yield of citronella oil found that the best extraction technique was by using the n-hexane solvent which yields essential oil much more than using ethanol and acetone solvents 27.

Based on the results and data analysis, it shows that the activity of the extracts is effective as repelant. However, the natural repelant effect against Culex quinquefasciatus mosquito bites is lower than the synthetic one. The synthetic repelant used in this study contained 13\% DEET as a positive control, with a higher repelantion strength than the treatment group. Based on these observations, it was shown the effect of the extracts was lower than the synthetic repelant.

The most widely used synthetic repelant contains 13\% DEET. DEET is a repelant in the aromatic amide group. The DEET compound works by blocking the receptors in the mosquito antenna, one 


\section{IJIM}

of which is the lactic acid receptor and can interfere with the mosquito olfactory receptors that mosquito avoid the exposed surface of these compounds ${ }^{28}$. However, DEET is toxin to human because of its properties can be absorbed into the body through the skin. Long-term use can be toxic to humans and can cause side effects such as dystonia, seizures, slurred speech, nausea, rashes, affected motor capacity, sensory disturbances, decreased learning ability and memory impairment. Use of a repelant containing DEET in high doses for a longer period of time can cause skin irritation, erythema, muscle cramps, and rash. Repeated use for a long time can cause systemic poisoning, which often occurs in children 29.

The advantages of insecticides of essential oils derived from plants are that their spectrum of biological activity is very broad, non-toxic, systemic, compatible, easily degraded, and safer than synthetic chemicals. The insecticides made from essential oils are also safe for the environment because they are not persistent. This is because the essential oils are easily broken down naturally that they do not last long in water, air, soil and the body of mammals. The essential oils are also effective against target organisms, compatible with other control methods, safe and non-toxic to non-target organisms as well as the environment and human health so that they have a huge potential to be developed as commercial plant-based insecticides ${ }^{30}$. The weakness of the insecticides containing essential oils is related to the properties of the essential oils themselves which are volatile and unstable or not resistant to sunlight. For example, cinnamaldehyde is unstable and will break down to form benzaldehyde at $60^{\circ} \mathrm{C}$. However, when combined with eugenol, cinnamaldehyde is stable to a temperature of $200^{\circ} \mathrm{C}$ for more than 30 minutes. The effectiveness of insecticides from essential oils is generally lower, the repulsion mechanism is slower than that of synthetic chemical insecticides ${ }^{31}$. Consequently, in an insecticide formula made from active essential oils, there are other chemical compounds that are always added to increase the stability of the active ingredient.

\section{CONCLUSION}

This study showed that the n-hexane extract from basil leaves and stems (Ocimum basilicum) was effective as a Culex quinquefasciatus mosquito repelant at a concentration of $31.52 \%$.

\section{REFERENCES}

1. Isman MB. Bridging the gap: Moving botanical insecticides from the laboratory to the farm. Ind Crops Prod. 2017;110(April):10-4.

2. Ahmed M, Peiwen Q, Gu Z, Liu Y, Sikandar A, Hussain D, et al. Insecticidal activity and biochemical composition of Citrullus colocynthis, Cannabis indica and Artemisia argyi extracts against cabbage aphid (Brevicoryne brassicae L.). Sci Rep. 2020;10(1):1-10.

3. Silverio MRS, Espindola LS, Lopes NP, Vieira PC. Plant natural products for the control of Aedes aegypti: The main vector of important arboviruses. Molecules. 2020;25(15).

4. Amoabeng BW, Johnson AC, Gurr GM. Natural enemy enhancement and botanical insecticide source: a review of dual use companion plants. Appl Entomol Zool. 2019;54(1):1-19. 
5. Campos EVR, Proença PLF, Oliveira JL, Bakshi M, Abhilash PC, Fraceto LF. Use of botanical insecticides for sustainable agriculture: Future perspectives. Ecol Indic. 2019;105:483-95.

6. Ponsankar A, Vasantha-Srinivasan P, Senthil-Nathan S, Thanigaivel A, Edwin ES, SelinRani S, et al. Target and non-target toxicity of botanical insecticide derived from Couroupita guianensis L. flower against generalist herbivore, Spodoptera litura Fab. and an earthworm, Eisenia foetida Savigny. Ecotoxicol Environ Saf. 2016;133:260-70.

7. Diop A, Diop YM, Thiaré DD, Cazier F, Sarr SO, Kasprowiak A, et al. Monitoring survey of the use patterns and pesticide residues on vegetables in the Niayes zone, Senegal. Chemosphere. 2016;144:1715-21.

8. Iskandar BS, Iskandar J, Partasasmita R, Irawan B. Various medicinal plants traded in the village market of karangwangi village, southern cianjur, west java, indonesia. Biodiversitas. 2020;21(9):4440-56.

9. Sankhalkar S, Vernekar V. Quantitative and Qualitative Analysis of Phenolic and Flavonoid Content in Moringa oleifera Lam and Ocimum tenuiflorum L. Pharmacognosy Res. 2016;8(1):16-21.

10. Chaudhary A, Sharma S, Mittal A, Gupta S, Dua A. Phytochemical and antioxidant profiling of Ocimum sanctum. J Food Sci Technol. 2020;57(10):3852-63.

11. Mierziak J, Kostyn K, Kulma A. Flavonoids as important molecules of plant interactions with the environment. Molecules. 2014;19(10):16240-65.

12. Farzaei MH, Bahramsoltani R, Ghobadi A, Farzaei F, Najafi F. Pharmacological activity of Mentha longifolia and its phytoconstituents. J Tradit Chinese Med. 2017;37(5):710-20.

13. Dirar AI, Alsaadi DHM, Wada M, Mohamed MA, Watanabe T, Devkota HP. Effects of extraction solvents on total phenolic and flavonoid contents and biological activities of extracts from Sudanese medicinal plants. South African J Bot. 2019;120:261-7.

14. IAEA. Guidelines for Standardised Mass Rearing of Anopheles Mosquitoes. In Vienna: Food and Agriculture Organization of the United Nations International Atomic Energy Agency Vienna; 2017. p. 44.

15. WHO. Guidelines for Efficacy Testing of Mosquito Repellents for Human Skin. Control of Neglected Tropical Diseases WHO Pesticide Evaluation Scheme.; 2009. 1-6 p.

16. Zaniol F, Calisto JFF, Cozzer G, Ferro DM, Dias JL, Rodrigues LGG, et al. Comparative larvicidal effect of Pterodon spp. extracts obtained by different extraction methods. J Supercrit Fluids. 2020;166.

17. Vinauger C, Lahondère C, Wolff GH, Locke LT, Liaw JE, Parrish JZ, et al. Modulation of host learning in Aedes aegypti mosquitoes. Curr Biol. 2018;28(3):333-344.e8.

18. Deletre E, Schatz B, Bourguet D, Chandre F, Williams L, Ratnadass A, et al. Prospects for repellent in pest control: current developments and future challenges. Chemoecology. 2016;26(4):127-42.

19. Ntalli N, Koliopoulos G, Giatropoulos A, Menkissoglu-Spiroudi U. Plant secondary metabolites against arthropods of medical importance. Phytochem Rev. 2019;18(5):1255-75.

20. Brito NF, Moreira MF, Melo ACA. A look inside odorant-binding proteins in insect chemoreception. J Insect Physiol. 2016;95:51-65.

21. Lombardo F, Salvemini M, Fiorillo C, Nolan T, Zwiebel LJ, Ribeiro JM, et al. Deciphering the olfactory repertoire of the tiger mosquito Aedes albopictus. BMC Genomics. 2017;18(1):1-23.

22. Zahran EM, Abdelmohsen UR, Khalil HE, Desoukey SY, Fouad MA, Kamel MS. Diversity, 


\section{IJIM}

phytochemical and medicinal potential of the genus Ocimum L. (Lamiaceae). Phytochem Rev. 2020;19(4):907-53.

23. Tzotzos G, Iley JN, Moore EA. New insights on repellent recognition by Anopheles gambiae odorant-binding protein 1. PLoS One. 2018;13(4):1-23.

24. Montell C, Zwiebel LJ. Mosquito Sensory Systems. In: Raikhel AS, editor. Progress in Mosquito Research. Science direct; 2016. p. 293-328. (Advances in Insect Physiology; vol. 51).

25. Tian H, Fürstenberg A, Huber T. Labeling and single-molecule methods to monitor G protein-coupled receptor dynamics. Chem Rev. 2017;117(1):186-245.

26. Bohbot JD, Jones PL, Wang G, Pitts RJ, Pask GM, Zwiebel LJ. Conservation of indole responsive odorant receptors in mosquitoes reveals an ancient olfactory trait. Chem Senses. 2010/10/18. 2011 Jan;36(2):149-60.

27. Demiray H, Tabanca N, Estep AS, Becnel JJ, Demirci B. Chemical composition of the essential oil and n-hexane extract of Stachys tmolea subsp. Tmolea Boiss., an endemic species of Turkey, and their mosquitocidal activity against dengue vector Aesdes aegypti. Saudi Pharm J. 2019 Sep;27(6):877-81.

28. Legeay S, Clere N, Apaire-Marchais V, Faure S, Lapied B. Unusual modes of action of the repellent DEET in insects highlight some human side effects. Eur J Pharmacol. 2018;825:92-8.

29. Swale DR, Sun B, Tong F, Bloomquist JR. Neurotoxicity and mode of action of N, NDiethyl-Meta-Toluamide (DEET). PLoS One. 2014;9(8):1-11.

30. Asbahani A El, Miladi K, Badri W, Sala M, Addi EHA, Casabianca H, et al. Essential oils: From extraction to encapsulation. Int J Pharm. 2015;483(1):220-43.

31. Chellappandian M, Vasantha-Srinivasan P, Senthil-Nathan S, Karthi S, Thanigaivel A, Ponsankar A, et al. Botanical essential oils and uses as mosquitocides and repellents against dengue. Environ Int. 2018;113:214-30. 
